\title{
INSERÇÃO INTERNACIONAL três temas na agenda brasileira
}

Meire Mathias

\begin{abstract}
Resumo: Propõe-se, aqui, uma reflexão sobre as estratégias de inserção internacional do Brasil, a partir de uma tríade de políticas componentes da Agenda diplomática. Nesse sentido, a análise se desenvolve desde o início dos anos 90, com a observação das orientações da nossa política externa para o Mercosul, para as negociações multilaterais, e em relação à proposta de constituição da Área de Livre Comércio das Américas (Alca). Palavras-chave: política externa; inserção internacional; diplomacia.
\end{abstract}

Abstract: A review of that part of Brazil's diplomatic agenda, which, through a three-pronged policy approach, seeks to secure Brazil's engagement in the international sphere. The analysis begins in the early 1990's, with an examination of Brazil's policy towards Mercosul, its multilateral negotiations, and with regard to its participation in FTAA.

Key words: foreign policy; international engagement; diplomacy.

A

título introdutório e para uma primeira aproximação com o tema central que será objeto de debate ao longo deste texto, entende-se que, em relação ao sistema internacional, o Brasil ocupa uma posição significativa no eixo principal de países que constituem o Mercosul, ${ }^{1}$ participa de instâncias multilaterais, como a Organização Mundial do Comércio (OMC), e também atua em diferentes foros internacionais e regionais, como a Organização das Nações Unidas (ONU) e o Grupo do Rio. No processo negociador da Alca, o Brasil é tido pelos Estados Unidos - nação formuladora desta proposta - como "um país de baixa relevância nas relações internacionais como um todo, à exceção de temas como meio ambiente, onde o país se destaca como um ator político de relevo. Em questões de alcance hemisférico ou regional, os EUA consideram o Brasil uma 'liderança natural' e um fator de estabilidade regional no contexto do Mercosul". ${ }^{2}$

O objetivo deste artigo é refletir sobre as estratégias de inserção internacional do Brasil a partir de uma tríade de políticas componentes da nossa Agenda externa. Desta forma, as discussões estão centradas nas orientações da política externa brasileira para o Mercosul, para as nego- ciações multilaterais e em relação à proposta de constituição da Área de Livre Comércio das Américas (Alca). Nesse sentido, parte-se da hipótese de que, com essa composição, é possível visualizar, mesmo que parcialmente, os parâmetros que norteiam a inserção internacional do país e como isso, mais recentemente, vem ocorrendo. A rigor, considerados isoladamente, esses temas representam diretrizes específicas de nossa política exterior, porém agregam-se e estão interpenetrados quando se aborda o sentido político-econômico do processo de inserção internacional do Brasil. Cabe igualmente esclarecer que a interpenetração não significa dependência entre os temas quanto ao seu encaminhamento, mas, na observação das ações externas do país, essas políticas aparecem mais do que imbricadas.

A interpretação da chancelaria brasileira sobre as estratégias de inserção internacional do Brasil, em linhas gerais, é a de que a América Latina é a nossa circunstância, todavia, o Mercosul é uma prioridade na Agenda. "O multilateralismo, por sua vez, é uma opção estratégica para as relações comerciais, sendo que a adesão à Alca deve ser negociada. É bem provável que, em virtude da opção pela adesão negociada, percebam-se resistências a esta pro- 
posta nos procedimentos adotados pelo Itamaraty, entretanto, esse posicionamento não implica a negação da Alca, o que significaria, em última instância, a não-adesão por parte do Brasil.

Há alguns anos, Roberto Abdenur (1994a) comentou que, a partir dos anos 90, o encaminhamento da política externa passou a sofrer enrijecimentos e pressões de várias ordens e que a diplomacia brasileira tomou consciência que, no cenário pós-guerra fria, "a importância relativa de cada país também é medida por sua projeção econômica, comercial, científica ou cultural, isso contudo, não nos parece que seja um elemento de comprometimento daqueles que fazem a agenda externa do país”. O diplomata procurou explicar que, dadas as condições deste contexto, o Brasil tem assumido uma posição mais flexível na definição de Agenda e alianças e, por isso, acredita ser necessário recuperar com realismo a expressão do ex-chanceler Ramiro Saraiva, que dizia: "o Brasil não dispõe de excedentes de poder". Em certo sentido, aproxima-se desta linha interpretativa Celso Lafer (1994), quando afirmou que, "o mundo, hoje, é muito mais importante estrategicamente para o Brasil do que o Brasil é relevante estrategicamente para o mundo". Mediante essas considerações, cunhadas por uma forte dose de realismo e pragmatismo, questiona-se qual é a importância estratégica do Brasil no cenário internacional? E mais. Quais são as possibilidades de uma inserção internacional favorável para o País?

Sem pretender esgotar as várias possibilidades que envolvem a formulação desta resposta, pode-se esboçar um desenho em que sejam traçados os processos que fazem parte desse debate, procurando dar visibilidade aos temas que são relevantes a esta questão. Antes porém, é preciso considerar que a totalidade de temas que compõem a Agenda externa do País, invariavelmente, é observada pela diplomacia brasileira com o objetivo de evitar que ocorram práticas incoerentes entre a condução de cada um destes temas e a orientação geral da política externa. Outra referência é que, no tratamento das diretrizes da política externa, observa-se a configuração, a dinâmica e as mudanças ocorridas no sistema internacional. Além disso, para a diplomacia é "pretensão legítima de todo trabalhador intelectual, desde Platão e Maquiavel até os mais modernos conselheiros do Príncipe, que seu esforço interpretativo possa conduzir a um melhor diagnóstico da realidade e, a partir daí, à conformação de um guia razoavelmente eficaz para a ação política dos dirigentes do Estado" (Almeida, 1991).
Para os membros do Itamaraty, a atuação diplomática é uma prática que se desenvolve no mundo exterior, muitas vezes com discrição, outras em sigilo, mas sempre negociando os interesses nacionais, construindo através da ação diplomática a imagem do País no sistema internacional. Segundo o embaixador Sérgio Bath, a dimensão da ação diplomática está relacionada à atuação de um especialista do Poder Executivo que executa a política externa, podendo ser interpretada como um instrumento de ajuste dos interesses do Estado. Para ele, "a importância da diplomacia reside na sua promessa de paz e ordem, pela solução razoável dos conflitos" (Bath, 1989).

Seguindo esta linha de raciocínio, pode-se considerar que o momento de paz significa ausência de guerra, porém, isso não implica a inexistência de interesses conflituosos, ou melhor, não há interesses assimétricos de natureza militar, tecnológica ou comercial, entre outros. A arte da política ${ }^{3}$ no exercício diplomático se traduz em pensamento estratégico que formula ações a partir das relações de poder e influência no cenário externo, seja ele global ou regional. Nesse sentido, diplomacia é ação sobre antagonismos e possibilidades, com diretrizes orientadas pelas realidades interna e externa que, no pós-guerra fria, encontram a Agenda dominada pelo econômico e pela confecção de regras para processos de transação internacional.

No Brasil, a partir dos anos 90, entre as diretrizes definidas para a política externa, está a inserção do País no Mercosul, que significa um aprofundamento de nossos compromissos político-econômicos junto aos países-membros. O multilateralismo é uma tendência que vem se acentuando ${ }^{4}$ desde o início do mesmo período, com o fortalecimento do papel de global trader do País. Em relação à Alca, a chancelaria brasileira tem divulgado, através dos meios de comunicação e em diferentes foros, que o maior interesse do Brasil, no momento, não é o de negociar datas e procedimentos de implementação do projeto, mas sim discutir a suspensão das medidas protecionistas americanas, em especial, no setor agrícola. Percebe-se que estas três frentes de atuação externa não são incompatíveis entre si ou em relação ao desenho de liberalização econômica traçado pelo governo brasileiro, sobretudo na última década.

Este debate, contudo, também tem origens no texto constitucional brasileiro de 1988 , que referenda a integração regional latino-americana e aponta que este seja um objetivo no estabelecimento de nossas relações externas. Constitucionalmente, determina-se que ocorram ações diplomáticas nesse sentido e que a análise da vida inter- 
nacional do País seja mediada por relações que perpassam pelo nacional e pelo regional. A rigor, a interpretação da opção regional para o Itamaraty é difícil de ser apreendida, considerando-se que esta instituição não manifestou seu posicionamento diante da nova diretriz constitucional. Entretanto, há declarações e considerações em textos produzidos por membros do Itamaraty que indicam pistas do entendimento diplomático sobre este tema. Por exemplo, o atual ministro das Relações Exteriores do Brasil afirma que a América Latina não é para nós uma mera opção diplomática, mas sim a nossa circunstância (Lafer, 1994). De acordo com os comentários do diplomata Fernando Guimarães Reis, o significado da expressão nossa circunstância está no fato de que, a partir da Constituição de 1988, as relações do País com a América Latina são singularizadas de tal forma que, para a política externa, a regionalização "não é uma prioridade excludente mas é certamente uma prioridade diferente, catalisadora, nervosa. Transita por ela a possibilidade de criar e operar outras prioridades" (Reis, 1994).

Estas declarações possibilitam algumas considerações referentes à interpretação da diplomacia sobre a questão da integração regional. Primeiramente, é importante perceber que a integração latino-americana não é, para os membros do Itamaraty, sinônimo de uma limitação nas relações exteriores do Brasil. Segundo, não se pode afirmar que a opção regional seja compreendida por estes como uma alavanca fundamental para a inserção do Brasil no sistema internacional. Tudo indica que a expressão nossa circunstância signifique a posição internacional do país circunscrita à configuração geopolítica e geoeconômica latino-americana. Nesse sentido, as possibilidades de inserção no cenário internacional dependem, em certa medida, do grau de mobilidade estratégica no contexto das relações de âmbito regional.

Entende-se, com isso, que as relações regionais são construídas pela diplomacia brasileira sob uma perspectiva estratégica, em que a nossa circunstância tem uma importância relativa e não é considerada um condicionante, que poderia representar imobilidade. Com estes parâmetros estabelecidos, nota-se que as diretrizes da política externa são elaboradas sem "engessamentos" dessa ordem. Ao contrário, com esse escopo, torna-se viável a condução de políticas orientadas para acordos bilaterais e regionais, bastante confluentes com o multilateralismo, permitindo ainda, que temas de grande amplitude e polêmicos, como é o caso da Alca, sejam tratados de maneira particular e no "tempo diplomático".
Com esses parâmetros, o Itamaraty pode orientar a política externa para a integração a partir de estratégias que se definem pelas contradições existentes no sistema regional, ou ainda pelas deficiências dos outros países que compõem o bloco. Nesse caso, assume-se uma posição política de competitividade e acirramento das diferenças. Diametralmente oposta à posição anterior, a política externa pode ser construída por estratégias que orientam a busca de melhoria nos indicadores socioeconômicos internos, que se somam à integração, no objetivo de contribuir para o crescimento da atividade econômica produtiva nacional. Desta forma, melhoram as condições de inserção regional e a manutenção da posição ocupada no interior da formação, dado o fortalecimento do poder político-econômico do País.

É válido considerar que a tomada de decisão sobre as estratégias de inserção compreende, em si, decisões de ordens política e econômica internas, bem como a consideração das decisões e estratégias tomadas pelos países envolvidos, a fim de medir as confluências e as divergências existentes no processo. Contudo, o andamento desse processo é estabelecido por categorias referentes à sua efetivação, como paz, cooperação e interesses políticoeconômicos combinados. O inverso, ou melhor, os interesses específicos e divergentes também estão presentes no processo negociador e tornam evidentes as tensões que dimensionam os limites do espaço cedido pelas partes.

\section{POLÍTICA EXTERNA E O MERCOSUL}

Quando o Brasil e a Argentina assinaram o Tratado Integração, Cooperação e Desenvolvimento, em 1988, os rumos do processo de disputa pela hegemonia regional foram alterados. $\mathrm{O}$ acordo previa, ao longo de dez anos, o estabelecimento de um espaço econômico comum traduzido pela eliminação de tarifas comerciais e de serviços, assim como a convergência entre políticas macroeconômicas. A opção estratégica da integração bilateral obedecia uma formulação diplomática, que se orientava por quatro princípios norteadores: realismo, gradualismo, flexibilidade e equilíbrio.

No início dos anos 90, ocorreu o aceleramento do processo de integração para o Mercosul. Com a assinatura do Tratado de Assunção, em março de 1991, a opção estratégica da integração passou a obedecer uma formulação diplomática orientada por três princípios norteadores: gradualismo, flexibilidade e equilíbrio. Estes são os fundamentos que sustentam a base do projeto de integração e 
são percebidos quanto à sua aplicabilidade, na definição de prazos e medidas adotadas, em face de algumas das alterações promovidas pelos países-membros em suas políticas macroeconômicas, bem como na opção dos instrumentos jurídicos que viabilizaram as etapas do período de transição que se sucedeu.

$\mathrm{Na}$ verdade, entre outros indicativos, o aceleramento na implementação do Mercosul ocorreu em virtude da formação dos grandes blocos econômicos, da alteração das relações Leste-Oeste e, nessa perspectiva, da redução da importância geopolítica da América Latina. Por outro lado, conforme as considerações de Renato L. R. Marques (1991), que na época era chefe da Divisão Econômica Latino-Americana do Ministério das Relações Exteriores, a integração regional fez com que se cumprisse o dispositivo incorporado no artigo 4, parágrafo único, da Constituição brasileira, "sendo também considerada como uma ferramenta valiosa para inserção mais competitiva das quatro economias no mercado internacional".

Distanciando-se da alternativa de integração hemisférica, desde aquele momento proposta pelos Estados Unidos, o Mercosul foi orientado pela estratégia de integração econômica sub-regional. Seu desenvolvimento foi conduzido sob o modelo de intergovernamentalismo, não tendo como meta criar instituições supranacionais de coordenação e fiscalização, a exemplo do que fez a União Econômica Européia - UEE e que poderia representar a democratização do processo de decisões. No seu bojo, o projeto estabelece alterações de ordem político-econômica que modificam a configuração regional, ao vincular o processo decisório ao conjunto dos quatro países, reduzindo o grau de autonomia para decisões individuais por parte dos Estados nacionais. Devido a esta configuração, no âmbito doméstico, a integração passa a ser um elemento estratégico relevante pois a dinâmica político-econômica fica vinculada, em maior ou menor grau, a esta formação.

É interessante perceber que, no processo decisório, criou-se um paradoxo, ${ }^{5}$ uma vez que tomam forma, na própria dinâmica da integração, questões com dimensões supranacionais, embora o modelo institucional adotado tenha um caráter intergovernamental. Mesmo assim, a supranacionalidade não foi discutida no âmbito do Mercosul. Ao que parece, jamais esteve em pauta a discussão sobre a formação de uma comunidade dos países sul-americanos, o que significa um envolvimento mais profundo da sociedade civil. Esta opção, ao que tudo indica, orientaria diferentemente tanto o processo deliberativo quanto a dinâmica de funcionamento da integração.
No cenário regional atual, o modelo intergovernamental é caracterizado pela exclusividade do poder de decisão, que permite ao Conselho Mercado Comum (CMC) e ao Grupo Mercado Comum (GMC) exercerem ação ordenadora na integração. $\mathrm{Na}$ verdade, esta centralização é viabilizada no transcorrer do processo de consolidação do Mercosul, pois os principais sujeitos deste projeto estão alocados no Ministério das Relações Exteriores, da Economia e do Banco Central de cada país membro, mantendo outros atores - como sindicalistas, intelectuais, empresários (sobretudo pequenos e médios) - distanciados do processo decisório. Isso significa que o poder de decisão do Executivo amplia-se com o projeto regional, uma vez que, para a estrutura técnico-burocrática regional, esta é a instância reconhecida como interlocutora para o encaminhamento de consultas e propostas em âmbito interno.

O contraponto desta discussão está no fato de que, hoje, diferentes atores organizados em associações empresariais, sindicatos e organizações não-governamentais, para citar somente alguns, debatem sobre a construção de formas de controle democrático da política externa. Fundamenta-se, cada vez mais, a crítica sobre o modelo tradicional de separação entre políticas interna e externa. Maria Regina Soares de Lima, por exemplo, argumenta que estão em curso um crescente interesse e uma maior participação da sociedade civil em temas da Agenda externa, pois ocorrem perdas e ganhos distributivos desiguais entre os diversos setores da sociedade. Isto posto, diz ela, "surgiu a necessidade de legitimação das posições assumidas na condução da política externa, a necessidade de um consenso e de garantir a credibilidade necessária para adotar determinadas políticas externas". ${ }^{6}$

Um outro aspecto a ser considerado sobre a participação da sociedade civil em temas da Agenda externa está nas discussões orientadas pela teoria institucionalista. Em linhas gerais, esta teorização pressupõe que os atores tem interesses comuns e que o grau de institucionalização em determinados setores da sociedade está aumentando, ${ }^{7}$ havendo, contudo, uma variação de grau nas instituições. Segundo Keohane (1999), teórico desta corrente, o termo instituições pode ser definido como sendo um "conjunto de regras permanentes e conectadas (formal ou informal) que definem papéis comportamentais, limitam a ação e compartilham expectativas". Essas considerações auxiliam a pensar a estrutura institucional do Mercosul como um canal (ou não) de representação das demandas advindas da sociedade e, em que medida, um resultado político depende das possibilidades e limites delineados pelas ins- 
tituições. Vale registrar que um dos pressupostos da teoria institucionalista é considerar que ação política envolve sujeitos e, por isso, instituições são estruturadas de ação com sentido, com lógica e por intermédio de processos.

\section{O GOVERNO BRASILEIRO DA NOVA REPÚBLICA AO BRASIL DO REAL}

No início dos anos 90, o presidente americano George Bush apresentou, no projeto Iniciativa para as Américas, uma alteração nas relações comerciais e econômicas entre os países latino-americanos e os Estados Unidos. Por esta razão, ocorreu o encontro que reuniu tecnocratas do governo norte-americano e de organismos financeiros internacionais como o FMI, Banco Mundial e o BID, no qual se realizou uma avaliação tanto das economias dos países latino-americanos quanto sobre o relacionamento político-econômico destes com os Estados Unidos. O objetivo dessa avaliação era medir as proporções e as possibilidades de pagamento da dívida externa latino-americana para com os organismos financeiros presentes naquela ocasião. O resultado deste encontro é o conhecido Consenso de Washington, ${ }^{8}$ que apresenta deliberações sobre as reformas tidas como necessárias por estas instituições e abrangem dez áreas específicas, como disciplina fiscal, redução dos gastos públicos, reforma tributária, liberalização financeira, investimento estrangeiro, privatizações, desregulamentação do mercado interno e de propriedade intelectual. Na perspectiva do Estado nacional, essas deliberações alteram a concepção de gestão de políticas públicas e provocam a redefinição do papel do Estado, obedecendo uma lógica de distanciamento paulatino de um modelo de Estado de Bem-Estar Social, em virtude da adoção do modelo neoliberal de gestão econômica e governamental.

Na gestão de Fernando Collor de Mello, o Brasil aderiu aos postulados consolidados no Consenso de Washington, promovendo, entre outras medidas, a abertura quase que unilateral do nosso mercado com a liberalização das importações. O governo brasileiro reforçou, através da chancelaria, ${ }^{9}$ o seu interesse de inserção internacional, com adequações no modelo político-econômico interno e de acordo com as diretrizes definidas na Iniciativa para as Américas. Por sua vez, o Ministério das Relações Exteriores passou a divulgar nos foros internacionais o posicionamento do Brasil em favor do fortalecimento do multilateralismo universal, buscando firmar o papel de global trader do país.
A gestão Collor apostou na liberalização comercial e reafirmou a sua posição em defesa ao sistema multilateral de comércio, privilegiando temas da Agenda externa com aspectos de natureza comercial, interessado nos efeitos e nos resultados comerciais para o país, como aumento do nível de comércio, dinamismo das importações e geração de fluxos comerciais. Contudo, é interessante observar os comentários feitos pelo embaixador Celso Amorim (1994a) sobre esses encaminhamentos do governo brasileiro, quando analisa este processo: "abrimos a nossa economia, mas não foi concedido, a não ser muito marginalmente, melhor acesso para nossos principais produtos de exportação no mercado norte-americano (contrariamente a uma das promessas fundamentais do discurso da Iniciativa para as América do presidente Bush)".

O fim do conturbado mandato do presidente Fernando Collor de Mello, marcado pelo seu impeachment, provocou, em âmbitos nacional e internacional, expectativas e incertezas quanto aos rumos que o País seguiria. O vicepresidente Itamar Franco assumiu o cargo em meio a controvérsias e, por isso, procurou pontuar não só o rompimento político com o seu antecessor, mas também, um novo governo para o Brasil. Naquele momento, ocorreram alterações de quadros no poder Executivo, que modificaram os rumos e a condução político-econômica do País. Segundo as considerações de Amado Luiz Cervo (1997), com a sua posse, voltou a público, no âmbito da política externa brasileira, "o pensamento precursor do processo de integração do Cone Sul, aquele que o subordinava não em primeiro lugar à criação de um mercado ampliado, mas ao apoio logístico aos sistemas produtivos nacionais num esforço de desenvolvimento sustentado".

Consoante com as mudanças em curso, a diplomacia brasileira reafirmou a continuidade e o fortalecimento do sistema de comércio internacional baseado em regras multilaterais, bem como, anunciou o interesse em aprofundar a iniciativa da integração regional como uma complementação do primeiro tema. Sobre esse aspecto, o ministro Celso Amorim viria a manifestar, em artigos e entrevistas, um novo enfoque sobre a política externa. Segundo ele, o comércio brasileiro é "distribuído de maneira homogênea pelas várias partes do mundo. Então para o Brasil, a regionalização nunca deve ser vista como condição de escala para lá chegar em condições competitivas. O Mercosul sempre foi concebido como um grupo econômico voltado para a competitividade externa, jamais como um bloco fechado"(Amorim, 1994b). Percebe-se, nestas considerações, que durante esta gestão, além do reforço ao sistema 
multilateral de comércio, a discussão sobre as diretrizes do Mercosul é intensificada, com o objetivo de convergir integração regional e comércio multilateral.

Nesta nova etapa política em que o país reforça suas características de global trader, somadas ao aquecimento do comércio no âmbito regional, emergem os elementos que levaram o presidente Itamar Franco a apresentar, em reunião do Grupo do Rio ${ }^{10}$ uma proposta de formação da Área de Livre Comércio Sul-Americano (Alcsa). A proposta, tendo por núcleo o Mercosul, visava congregar, em um prazo de dez anos, os países de Iniciativa Amazônica, do Grupo Andino e o Chile. O Brasil propôs uma alteração no dinamismo da integração a partir da ampliação em leque pela América Latina, primeiro com a inclusão do Chile e da Bolívia ao Mercosul e depois com a afetiva criação da Alcsa. Do ponto de vista estratégico, isso aumentaria o grau de mobilidade político-econômica latino-americana diante dos Estados Unidos, bem como projetaria uma efetiva possibilidade de criar mecanismos de controle regional que favorecessem o desenvolvimento sulamericano a partir da associação de objetivos.

Nesta linha propositiva, durante o mesmo governo, temse um segundo eixo de ação externa relacionado ao avanço do processo de cooperação entre o Mercosul e a UEE - União Econômica Européia. ${ }^{11}$ Segundo as considerações do ministro Celso Amorim (1994b), o empenho do Brasil em consolidar os entendimentos entre os dois blocos reafirma a idéia de que "a concertação hemisférica não diminui o interesse e a prioridade de nossas relações com as potências européias".

Vale ressaltar que, nesse mesmo período, a proposta americana de criação da Alca é recebida pela diplomacia brasileira com prudência, por fomentar dependência econômica aos Estados Unidos e restringir a autonomia da política nacional de desenvolvimento junto ao Mercosul e ao projeto Alcsa. Após a Conferência da Cúpula das Américas em Miami, o secretário-geral das Relações Exteriores no Governo Itamar Franco, Roberto Abdenur, escreveu um longo artigo, confirmando, entre outros posicionamentos, que para o Brasil a parceria hemisférica é vista com realismo e prudência. Ressalte-se ainda que, desde esta I Conferência, o país defende o calendário que estabelece a criação da Alca em 2005, por entender que este cronograma "resguarda de perturbações indesejáveis os trabalhos de consolidação dos agrupamentos e iniciativas sub-regionais de integração já existentes, ou em marcha, como, no que interessa ao Brasil, o Mercosul e a Alcsa" (Abdenur, 1994b).
Não se pode afirmar que, durante essa gestão de transição, tenha ocorrido uma alteração nas concepções brasileiras sobre o projeto Mercosul, entretanto, há evidências de que, neste período, a política externa diminuiu a distância entre os temas da Agenda sobre comércio regional e multilateral do país, bem como criou novas relações econômicas fora do eixo América do Sul-América do Norte. De certa forma, esta iniciativa foi mais propositiva diante do processo de globalização em relação à gestão anterior, que assumiu uma postura mais reativa no sentido de adequações às regras internacionalmente estabelecidas.

Retomando algumas análises sobre o período, relativas ao tema sobre política externa e desenvolvimento, o ministro Celso Amorim criticou a forma que o governo Collor realizou a liberalização da economia brasileira. De acordo com os seus argumentos, o predomínio do neoliberalismo contribuiu para corrigir distorções em relação ao papel do Estado, porém agravou as dificuldades no campo social, atingindo diretamente o significado do conceito de desenvolvimento. É também por esta razão que, na 47 a seção da ONU, em 1993, o Brasil apresentou a proposta de que os problemas referentes ao desenvolvimento fossem apreciados e incluídos nas discussões da Agenda para o Desenvolvimento. A proposta para a retomada do crescimento econômico nos países latino-americanos possuía três eixos indicativos para atuação: um de ordem interna, referente às necessidades e possibilidades nacionais de cada país; um no campo internacional, implicando o fortalecimento do comércio multilateral através da revisão dos critérios de concessão de empréstimos e acesso desimpedido à tecnologia de ponta para fins pacíficos; e o último, relacionado diretamente à $\mathrm{ONU}$, no sentido de promover uma agenda temática específica, com estratégias de apoio encaminhadas pela própria entidade.

Percebe-se que a interpretação das questões referentes às estratégias de inserção internacional do Brasil e dos países da América Latina, realizada pelo segundo ministro das Relações Exteriores do Governo Itamar, possui diferenças significativas em relação àquelas apresentadas pelo primeiro ministro das Relações Exteriores do Governo Fernando Henrique Cardoso. A rigor, o embaixador Celso Amorim desenvolveu suas considerações sobre o Mercosul, multilateralismo e América Latina a partir de categorias referentes ao desenvolvimento econômico-produtivo, dependência econômica externa relativa e atenção especial para as relações político-econômicas entre países latino-americanos. Ao que parece, Luiz Felipe Lampreia, remeteu a importância desses mesmos temas da Agenda 
para os aspectos positivos (ou confluentes) que esses possuem para a atuação no mercado econômico-financeiro.

Para o embaixador Lampreia, a trajetória percorrida pelo Mercosul desempenhou um papel fundamental no processo de integração regional enquanto fator de ampliação dos mercados preferenciais. Méritos, segundo ele, obtidos a partir do estabelecimento de prioridades em nossa Agenda, em que se buscou, com a ação externa, defender o fortalecimento do multilateralismo econômico e a construção do relacionamento bilateral com os três grandes blocos econômicos representados pela UEE, pelo Nafta e pelo Japão, sem contudo deixar de garantir a continuidade de relacionamento em nossa área mais imediata de convivência internacional, qual seja, a América Latina. Em suas considerações, o embaixador fez o contraponto entre dificuldades conjunturais e os desajustes estruturais internos que balizam as referências e a interpretação da nação no nível internacional. Entretanto, Lampreia (1993) também justifica a lógica do sistema internacional globalizado, dizendo que diante da "dependência crescente que temos em relação aos influxos provenientes do quadro externo, estejamos limitados e condicionados severamente em nossas alternativas individuais".

$\mathrm{Na}$ verdade, as concepções no tocante à política externa brasileira entre os dois ex-ministros transparecem em outros momentos em que ambos reafirmam diferentes pontos de vista. Na cerimônia de transmissão de cargo de ministro das Relações Exteriores, por exemplo, o embaixador Celso Amorim fez um balanço sobre sua atuação no cargo e afirmou que, "a diplomacia do Governo Itamar Franco sempre teve como referência um Brasil politicamente estável, economicamente dinâmico, consciente de seus problemas na área social". ${ }^{12}$ Já o embaixador Luiz Felipe Lampreia insinuou, na cerimônia em que tomava posse do cargo de ministro de Estado, que, diferentemente do Governo Itamar Franco, o presidente Fernando Henrique Cardoso valoriza o papel da diplomacia e proporciona o estreitamento das relações entre o governo e o Itamaraty. Ele anunciava ali que a diplomacia brasileira, na sua atuação externa, passaria a operar mediante a participação do presidente da República e justificou: "a diplomacia de Chefes de Estado e Governo é a marca das relações internacionais contemporâneas e uma característica particularmente importante da diplomacia hemisférica" ${ }^{13}$

Não há dúvidas de que, desde 1995, o governo brasileiro tem demonstrado um posicionamento favorável às tendências da ordem internacional, o que caracteriza sua gestão pelo aprofundamento dos mecanismos de adaptação à era da globalização. A gestão Fernando Henrique também enfatiza o papel de global trader do País e defende uma estratégia de inserção internacional orientada para a abertura de novas frentes de comércio internacional e pela liberalização de fluxos de capital financeiro. Para a chancelaria, a globalização deve ser interpretada como um fenômeno que funciona como um mecanismo ordenador das relações internacionais e provoca, no âmbito interno, o enfrentamento de forças em um movimento de alteração das estruturas, dos comportamentos, das mentalidades e dos objetivos nacionais. Nesta perspectiva, o Estado brasileiro deve mover-se "abrindo o seu acesso aos mercados internacionais, alargando o leque de parcerias operacionais e atraindo investimentos externos" (Lampreia, 1995).

O governo Fernando Henrique, determinado a corrigir aquilo que interpreta como sendo indícios de desequilíbrios macroeconômicos que retardam e, ao mesmo tempo, constituem uma ameaça à sustentabilidade de um processo de liberalização, promove um novo ciclo de privatizações das empresas públicas, ajustes fiscais e cortes orçamentários, sobretudo aqueles destinados a programas sociais como educação, saúde e infra-estrutura. Estas medidas reduzem, ainda mais, a intervenção do Estado no âmbito socioeconômico e cedem espaço para as forças de mercado, o que significa a "reposição às idéias de apoio ao capitalismo globalizante", como bem coloca Amado Luiz Cervo (1997).

Cabe recordar que o ministro Luiz Felipe Lampreia, na sessão inaugural do Conselho Geral da OMC, afirmou que o Brasil defende a prevalência do sistema multilateral de comércio e, neste sentido, o governo pretende desenvolver projetos que dêem continuidade às reformas macroeconômicas e aos compromissos de liberalização da economia. No mesmo discurso, relativizou a capacidade de poder e influência do Mercosul no cenário internacional, dizendo que esse o projeto foi instituído não para proteger as economias de seus integrantes, mas sim para transformá-las e liberalizá-las. No final, Lampreia reiterou a disposição do Governo do presidente Fernando Henrique de "colaborar para o surgimento de um entorno econômico em que as forças de mercado tenham função preponderante na alocação de recursos produtivos, reduzindo-se a intervenção governamental a corrigir falhas desse mercado e a garantir a prevalência das condições de competitividade". ${ }^{14}$

\section{APONTAMENTOS PARA UM DEBATE...}

Contemporaneamente, o movimento de globalização propõe uma interdependência econômica entre os países 
em que a estruturação do capitalismo deve corresponder ao que se refere não só aos fluxos de capitais, de mercadorias e de serviços, mas também ao capital produtivo. Prova disso é o aumento do número de empresas de natureza transnacional que, com a sua expansão, alteram a localização espacial da produção.

$\mathrm{Na}$ verdade, a reestruturação dos processos de produção e de circulação de mercadorias e o fortalecimento da hegemonia do capital financeiro têm o objetivo de recuperar e redimensionar a acumulação do capital. A interferência desse processo econômico mundial está refletido no Estado nacional, através da perda de poder de intervenção e regulação sobre as formas de produção e distribuição de renda, afetando violentamente a esfera pública e social. ${ }^{15}$ Paralelamente, os pólos de poder econômicofinanceiro mantêm a vanguarda na chamada revolução tecnológica e reafirmam estrategicamente "a dominação sobre a economia dos países periféricos (o que também é reforçado pela dependência desses quanto à importação de capitais)" (Vizentini, 1990).

No Brasil, a ação externa do Estado está legitimada pelo Estado Democrático de Direito e pela representatividade das instituições governamentais, que atribuem ao corpo diplomático o papel de conduzir as diretrizes definidas para a política externa. Entretanto, a formulação dessas diretrizes pode, em tese, ser encaminhada por um número ampliado de sujeitos. A confirmação desta hipótese pressupõe que o processo de formulação da política externa seja concebido como algo dinâmico e em construção, tanto pelas relações humanas quanto pelas relações de poder. Segundo considerações de Tullo Vigevani (1999), esta concepção é vital para que se possa "pensar as relações internacionais não apenas dando-se entre Estados, mas também entre seres humanos".

Esta é uma discussão de extrema complexidade, pois nela está implícita a negação ou a aceitação de uma abertura no processo decisório sobre as diretrizes políticas externas e implica que os temas da Agenda sejam discutidos e definidos direta e o mais amplamente possível, com os diversos segmentos organizados da sociedade, ou ainda, por meio da participação propositiva dos representantes parlamentares, na esfera nacional. Justamente este é o ponto de mutação em que, através da participação de um número maior de sujeitos, o espaço de articulação política pode ser ampliado, legítima e autonomamente. Com isso, as possibilidades e expectativas nacionais referentes ao projeto Mercosul, às relações comerciais multilaterais e quanto aos planos bi-regionais (Alca e UEE), podem ser definidas pelo conjunto da sociedade com maior lucidez e qualidade de análise.

Deve-se considerar ainda que, em virtude do ataque aos Estados Unidos, em 11 de setembro de 2001, as projeções sobre o plano internacional alteraram-se. Como bem colocou Emir Sader (2001), "pela primeira vez os EUA reinam sozinhos como superpotência e têm dificuldades para fazer uso da sua força". Os desdobramentos deste ataque ainda são imprevisíveis, tendo-se somente a certeza de que mudou a dinâmica do sistema internacional. Neste momento, a Agenda diplomática releva os temas referentes à Segurança Nacional, em consideração da forte tendência de endurecimento da situação internacional e da posição preponderante dos Estados Unidos em favor da militarização dos conflitos.

No entanto, é razoável pensar em uma outra tendência no curso desse processo, fortalecida pela defesa dos direitos humanos, pela solução pacificamente negociada dos conflitos, pela continuidade do sistema de cooperação internacional. Ou seja, uma tendência em defesa da multipolaridade no sistema internacional e contra ações terroristas, mas contrapondo-se ao unipolarismo no sistema e de propostas defensoras da superioridade militar em processos de paz.

Neste cenário, a postura externa do Brasil deve ser de respeito aos seus princípios de relações internacionais que são: independência nacional; prevalência dos direitos humanos; autodeterminação dos povos; não-intervenção; igualdade entre os Estados; defesa da paz; solução pacífica dos conflitos; repúdio ao terrorismo e ao racismo; cooperação entre os povos para progresso da humanidade; concessão de asilo político. Mas, este é um outro debate...

\section{NOTAS}

1. O Brasil compõe o eixo principal com a Argentina. O eixo secundário é composto pelo Paraguai e Uruguai.

2. Comentário feito pelo Embaixador do Brasil em Washington, Rubens Antonio Barbosa, em evento do Centro Brasileiro de Relações Internacionais (Cebri) e do Conselho de Empresários para a América Latina (Ceal), em 06/08/01 (Cebri, 15/08/01).

3. Recuperando os conceitos de Virtú e Fortú, formulados por N. Maquiavel, em $O$ Príncipe.

4. Para aprofundar este debate, ver Miyamoto (2000).

5. Para aprofundar este debate, ver Mathias (1999).

6. Anais Fórum Continental Área de Livre Comércio das América: atores políticos nos processo de integração. Realizado no Parlatino LatinoAmericano, entre 27 e 29/11/2000, em São Paulo.

7. Para aprofundar este debate, ver Vigevani (1999). 
8. Para aprofundar este debate, ver Batista (1994).

9. Durante esta gestão de Governo estiveram no cargo de ministro das Relações Exteriores, o embaixador Francisco Rezek e, posteriormente, o embaixador Celso Lafer.

10. Realizada em outubro de 1993, em Santiago, Chile.

11. Em 1992, Mercosul e UEE assinam o Acordo Interinstitucional, que abriu o diálogo de aproximação entre os dois grupos. Em 1994, foi assinada uma Declaração Conjunta Solene.

12. Discurso do ministro das Relações Exteriores, embaixador Celso Amorim, por ocasião da cerimônia de transmissão de cargo. Palácio do Itamaraty, 02/01/1995.

13. Discurso por ocasião de sua posse como ministro de Estado das Relações Exteriores. Palácio do Itamaraty, 02/01/1995.

14. Discurso do ministro das Relações Exteriores, na OMC, em Genebra, em 31/01/1995.

15. Para aprofundar este debate, ver Castro (1999).

\section{REFERÊNCIAS BIBLIOGRÁFICAS}

ABDENUR, R. "Projeção externa do Brasil depende do poder da diplomacia”. Carta Internacional. São Paulo, Ed. USP, 13/09/1994. $19 / 12 / 1994$

ALMEIDA, P.R. de. "Relações internacionais do Brasil: introdução metodológica a um estudo global". Contexto Internacional. Rio de Janeiro, Ed. PUC-Rio, v.13, n.2, jul.-dez. 1991, p.161-85.

AMORIM, C. "Política externa, o legado do Governo Itamar". Jornal do Brasil. Rio de Janeiro, 10/01/1994.

. "Estados Unidos: percepções e realidades". Jornal do Brasil. Rio de Janeiro, 23/12/1994.

BATISTA, P.N. O Consenso de Washington: a visão neoliberal dos problemas latino-americanos. São Paulo, Pedex, Caderno 6, 1994.

BATH, S. O que é diplomacia. São Paulo, Brasiliense, 1989.

CASTRO, R.P. "Globalização, e visão unidimensional (monetarista) do mundo moderno". Novos Rumos. São Paulo, IAP-Ipso, Ano 14, n.31, 1999, p.10-17.
CEBRI - Centro Brasileiro de Relações Internacionais. Boletim Cebri, n. $13,15 / 08 / 01$

CERVO, A.L. "Política de comércio exterior e desenvolvimento: a experiência brasileira". Revista Brasileira de Política Internacional. Brasília, ano 40, n.2, 1997, p.5-26.

KEOHANE, R. "Neoliberal institucionalism: a perspective on word politics ”. In: VIGEVANI, T. (coord.). Relatório Mercosul: a emergência de uma nova sociedade. São Paulo, CNPq/Cedec, cap.4,1999, mimeo.

LAFER, C. "Política externa brasileira: reflexão e ação". Cooperação Internacional: estratégia e gestão. São Paulo, Ed. USP, 1994, p.23-43.

LAMPREIA, L.F. O Brasil e o atual ordenamento político econômico mundial. Brasília, MRE/Funag/Ipri, Caderno 7, jun. 1993, p.6-39.

"A política externa do Governo Fernando Henrique". Jornal do Brasil. Rio de Janeiro, 08/01/1995.

MARQUES, R.L.R. "Mercosul: origens, evoluções e desafios". Boletim de diplomacia econômica. Brasília, MRE/GET, n.5, out.-jan. 1991, p.3-6.

MATHIAS, M. Brasil e Mercosul: paradoxos de uma politica externa. Dissertação de Mestrado. São Paulo, PUC-SP, 1999.

MIYAMOTO, S. O Brasil e as Negociações Multilaterais. Campinas, IFCH/Unicamp, Primeira Versão, n.93, out. 2000.

REIS, F.G. "O Brasil e a América Latina”. Temas de politica externa brasileira. São Paulo, MRE/Funag/Paz e Terra, v.II, 1994 p.9-41.

SADER, E. “O império contra-ataca? Contra quem?" Jornal do Brasil. Rio de Janeiro, 12/09/2001.

VIGEVANI, T. "Os ciclos longos da sociedade internacional e suas conseqüências contemporâneas". Lua Nova. São Paulo, Cedec, n.46, 1999, p.5-9.

VIZENTINI, P.G.F. "Crise e transição: o contexto internacional das integrações regionais”. In: SEITENFUS, V.M. e BONI, L.A. Temas de integração latino-americana. São Paulo, Vozes, 1990, p.11-31.

Meire Mathias: Socióloga, Professora das Faculdades Integradas Teresa Martin. 